\title{
Estimativa de áreas de risco para hepatite $\mathrm{A}$
}

\author{
Estimation of risk areas for hepatitis A
}

\author{
1 Serviço de Epidemiologia, \\ Hospital dos Servidores do \\ Estado, Rio de Janeiro, Brasil. \\ 2 Núcleo de Estudos de Saúde \\ Coletiva, Universidade \\ Federal do Rio de Janeiro, \\ Brasil. \\ Correspondência \\ R. C. C. Braga \\ Servico de Epidemiologia, \\ Hospital dos Servidores do \\ Estado. \\ Av. Brasil 17241, bloco 2 , \\ apto. 404, Rio de Janeiro, $R J$ \\ 21241-051, Brasil. \\ rbiobraga@globo.com
}

\section{Abstract}

This study estimated hepatitis A risk areas in a region of Duque de Caxias, Rio de Janeiro State, Brazil. A cross-sectional study consisting of a hepatitis A serological survey and a household survey were conducted in 19 census tracts. Of these, 11 tracts were selected and 1,298 children from one to ten years of age were included in the study. Geostatistical techniques allowed modeling the spatial continuity of hepatitis A, non-use of filtered drinking water, time since installation of running water, and number of water taps per household and their spatial estimation through ordinary and indicator kriging. Adjusted models for the outcome and socioeconomic variables were isotropic; risk maps were constructed; crossvalidation of the four models was satisfactory. Spatial estimation using the kriging method detected areas with increased risk of hepatitis A, independently of the urban administrative area in which the census tracts were located.

Hepatitis A; Risk Zone; Geographic Information Systems
Ricardo Cerqueira Campos Braga 1

Luís Iván Ortiz Valencia 2

Roberto de Andrade Medronho 2

Claudia Caminha Escosteguy 1

\section{Introdução}

A hepatite A é causada pelo vírus A da hepatite (HAV), um Picornaviridae do gênero Hepatovirus. Existem sete genótipos virais, sendo que quatro infectam o homem e os mais freqüentemente encontrados nestas infecções são os genótipos I e III 1. Embora a doença seja conhecida desde as antigas civilizações chinesa, grega e romana, o primeiro relato escrito foi o de uma epidemia na ilha de Minorca, Espanha, no século XVIII ${ }^{2}$. O vírus pode ser encontrado em água potável, mar e solo, sendo resistente no ambiente e sua infecciosidade é de até duas semanas 3. A infecção é transmitida por via fecal-oral, água, alimentos e disseminação de pessoa a pessoa. Condições precárias de saneamento e higiene favorecem infecções entéricas. O período de incubação da doença varia entre 15 e 45 dias. A clínica é assintomática em $90 \%$ dos casos adultos 4,5 e pode variar até a forma mais grave com letalidade inferior a $1 \% 6$.

A incidência mundial excede 1,4 milhão de casos por ano ${ }^{7}$. A susceptibilidade é universal, sem diferenças entre os sexos e raças. Em função de a alta prevalência estar associada a precárias condições sócio-econômicas, principalmente, de higiene e de saneamento 8,9,10,11, constituise em um indicador de condições sanitárias da população. Assim, a melhoria dessas condições pode reduzir a transmissão pessoa a pessoa, diminuindo sua força de infecção 12 . Os anticorpos 
contra o vírus da hepatite A (anti-HAV) são detectados no sangue e a soroprevalência aumenta com a idade 13,14.

É reconhecida a importância de estudos da distribuição geográfica de doenças para o planejamento e tomada de decisões em sistemas de vigilância epidemiológica. Sistemas de informação em saúde que usam tecnologias de aquisição, processamento e análise de informação espacial ainda são inovadores em muitos países em desenvolvimento. O Sistema de Informação Geográfica (SIG) é a ferramenta central em estudos que avaliam a distribuição geográfica de uma doença. O SIG proporciona uma ampla variedade de procedimentos e métodos para coleta, armazenamento, visualização e análise de dados espaciais 15,16 .

Em áreas urbanas, a distribuição espacial e temporal dos casos de uma doença pode ser influenciada por uma combinação de fatores geográficos, climáticos, biológicos e antrópicos. Usualmente, estatísticas dos casos de doença, e de algumas co-variáveis, estão disponíveis como dados agregados definidos sobre unidades geopolíticas. Por exemplo, setor censitário, bairro ou região administrativa. A variação espacial da ocorrência da doença pode ser significativa ainda dentro dessas áreas 17. Quando dispomos de informação georreferenciada no nível individual, preferencialmente, obtida com base em um processo de amostragem, podemos estimar o risco da ocorrência de uma doença em toda a área de estudo usando-se métodos geoestatísticos 18 .

Este trabalho teve como objetivo estimar áreas de risco para a ocorrência de hepatite A em uma região carente na cidade do Rio de Janeiro, Brasil, e a associação espacial com variáveis sócio-econômicas e peridomiciliares.

\section{Materiais e métodos}

Para estimar a soroprevalência do anticorpo contra o HAV foi desenvolvido um estudo seccional (inquéritos soroepidemiológico e domiciliar) na área de abrangência do Programa de Despoluição da Baía de Guanabara (PDBG), para uma amostra da população dos 19 setores censitários pertencentes a uma localidade de Campos Elyseos, denominada de Parque Fluminense, segundo distrito do Município de Duque de Caxias, Rio de Janeiro, Brasil. A coleta de dados se realizou de julho a dezembro de 1997.

Esses inquéritos foram realizados pelo Projeto de Avaliação dos Impactos Sobre as Condições de Saúde e Qualidade de Vida do PDBG (PAISQUA), desenvolvido pelo Núcleo de Estudos de Saúde
Coletiva (NESC), Universidade Federal do Rio de Janeiro (UFRJ).

O plano amostral do PAISQUA 19 considerou a necessidade de selecionar 13 amostras aleatórias simples independentes, uma para cada grupo etário de interesse, a saber: 1, 2, 3, 4, 5, 6, 7, 8, 9, 10-14, 15-19, 20-29, 30 anos ou mais, em função das distintas soroprevalências encontradas para cada um destes estratos em um estudo piloto realizado previamente. Assim, 3.271 amostras de soro foram coletadas em indivíduos de 1 a 83 anos de idade.

Neste trabalho, optou-se por selecionar 11 dos 19 setores censitários escolhidos pelo PAISQUA, em função de representarem uma região contígua com diferentes cotas altimétricas. Essa área possui uma população com precárias condições sócio-econômicas, instalações sanitárias deficientes, elevada concentração populacional e um alto grau de poluição orgânica peridomiciliar. Além disso, optou-se por analisar apenas as crianças com idade igual ou maior que 1 ano e menor que 10, perfazendo um total de 1.298 indivíduos incluídos no presente trabalho. Por meio da restituição aerofotogramétrica da área de estudo, cada caso foi georreferenciado no centróide de seu respectivo domicílio em um mapa com escala 1:2.000. A área de estudo e a posição espacial dos casos na amostra são apresentados na Figura 1.

Por intermédio de um inquérito soroepidemiológico e domiciliar avaliaram-se as condições sócio-econômicas, sanitárias peri e intradomiciliares das crianças selecionadas na amostra. A coleta de sangue foi realizada por punção digital usando-se uma lanceta automática (Glucolet, Bayer), armazenado em tiras de papel de filtro ( $\mathrm{n}^{\circ}$. 1, Whatman, Reino Unido) e analisado pelo método ELISA (ETI-AB-HAVK-3, Sorin Biomédica Diagnostics S.p.A., Itália) 20. Esse método foi previamente validado por Almeida et al. 21 . Antes da realização dos exames, o responsável pela criança foi informado sobre os objetivos do trabalho e, no caso de concordância, assinou o termo de consentimento. O estudo foi aprovado pelo Comitê de Ética em Pesquisa do NESC/ UFRJ.

As variáveis consideradas foram: não uso de filtro, número de pontos de água do domicílio, tempo de encanamento do domicílio em anos, idade da criança em anos, ausência de ligação do domicílio com a Companhia Estadual de Águas e Esgotos do Rio de Janeiro (CEDAE), ausência de saneamento público, ausência de cozinha e banheiro, densidade de moradores por cômodo, renda familiar em salários mínimos (valor de 1997: R\$ 120,00) e altitude do domicílio sobre o nível do mar em metros. 
Área de estudo dividida em setores censitários (número do setor em detalhe) e posição espacial dos casos positivos e negativos de anti-HAV da amostra. Duque de Caxias, Rio de Janeiro, Brasil, 1997.

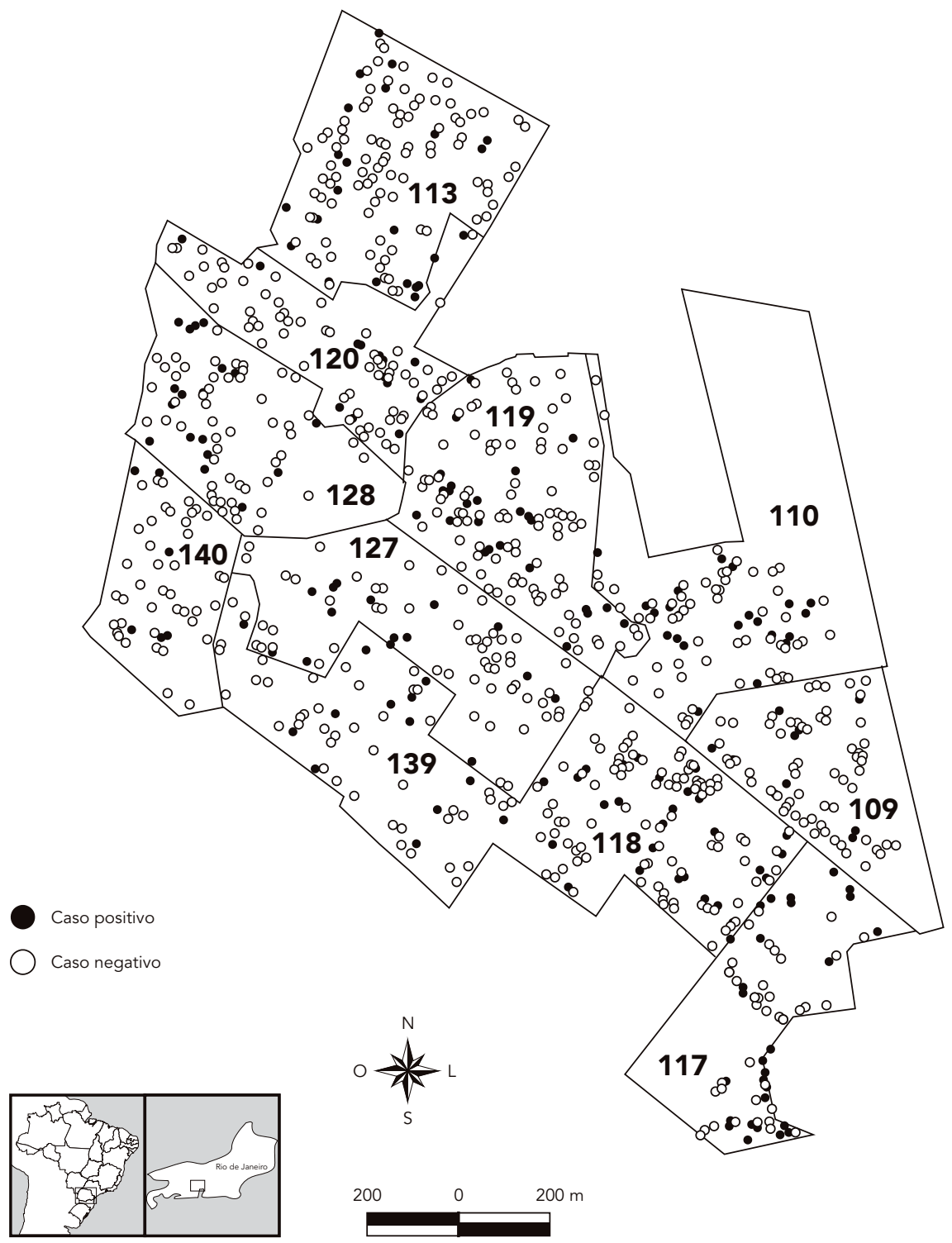

As variáveis analisadas espacialmente pelo método geoestatístico foram: hepatite A, não uso de filtro, número de pontos de água no domicílio e tempo de encanamento de água no domicílio. Para tal, uma função indicadora foi definida para as variáveis categóricas considerando-se o valor 1 para o caso positivo de hepatite $\mathrm{A}$ (ou de não uso de filtro) e 0 para o caso alternativo respectivamente. Basicamente, a análise geoestatística consiste em duas etapas. A primeira consiste na modelagem da continuidade espacial, sendo esta um elemento intrínseco da distribuição espacial dos casos de uma doença, ou de qualquer outro fenômeno espacial. Esse conceito estabelece que valores de um fenômeno natural em posições próximas tendem a ser mais similares que valores em posições mais afastadas. A continuidade espacial foi estimada segundo a construção de 
semivariogramas experimentais para um número determinado de direções e distâncias, e o ajuste de um modelo de semivariograma. Na etapa seguinte, a variável é espacializada em toda a área de estudo usando-se um método de estimativa espacial, denominado de krigagem, ou por meio de simulação estocástica espacial 22.

Considerou-se o estimador do semivariograma experimental para uma variável $\mathrm{z}($.) definido por:

$\hat{\gamma}(\mathrm{h})=\frac{1}{2|\mathrm{~N}(\mathrm{~h})|} \sum_{\mathrm{N}(\mathrm{h})}\left(\mathrm{Z}\left(\mathrm{s}_{\mathrm{i}}\right)-\mathrm{Z}\left(\mathrm{s}_{\mathrm{j}}\right)\right)^{2}$

em que $|\mathrm{N}(\mathrm{h})|$ é o número de pares de dados pertencentes a uma região de tolerância para um vetor h. Como as posições espaciais nessa amostra não formavam uma grade regular, regiões de tolerância para uma determinada distância e ângulo foram usadas para o cálculo dos semivariogramas experimentais para as direções norte-sul (NS) e leste-oeste (EO).

A modelagem do semivariograma ajustou um modelo exponencial, definido por:

$\gamma(h)=\left\{\begin{array}{cc}0 & h=0 \\ C_{o}+C\left[1-\exp \left(-\frac{3 h}{a}\right)\right] & h>0\end{array}\right.$

Os parâmetros do modelo são: o alcance (a), o patamar $\left(\mathrm{C}_{\mathrm{o}}+\mathrm{C}\right)$, a contribuição $(\mathrm{C})$ e o efeito pepita $\left(\mathrm{C}_{\mathrm{o}}\right) . \mathrm{O}$ alcance define a máxima distância em que a variável é correlacionada. O patamar identifica o limite na variabilidade espacial para grandes distâncias. A contribuição (C) corresponde ao componente da variabilidade espacial que é modelado. $\mathrm{O}$ efeito pepita define o componente da variabilidade espacial presente em distâncias menores que a mínima distância entre elementos na amostra, e também, erros de medição.

$\mathrm{O}$ risco de hepatite $\mathrm{A}$ e do não uso de filtro foi estimado espacialmente usando-se krigagem indicadora (KI). A KI estima a probabilidade de ocorrência de um caso positivo numa posição não observada $\mathrm{s}_{\mathrm{o}}$ utilizando-se os valores das observações vizinhas. O preditor de KI é definido pela seguinte expressão:

$\mathrm{p}_{\text {IK }}\left(\mathrm{s}_{\mathrm{o}}\right)=\sum_{\mathrm{i}=1}^{\mathrm{n}} \lambda_{\mathrm{i}}\left(\mathrm{s}_{\mathrm{o}}\right) \mathrm{I}\left(\mathrm{s}_{\mathrm{i}}\right)$

em que $\left\{\mathrm{I}\left(\mathrm{S}_{1}\right), \ldots, \mathrm{I}\left(\mathrm{S}_{\mathrm{n}}\right)\right\}$ são dados indicadores numa vizinhança de $\mathrm{s}_{\mathrm{o}}$ e $\left\{\lambda_{1}\left(\mathrm{~S}_{\mathrm{o}}\right), \ldots, \lambda_{\mathrm{n}}\left(\mathrm{S}_{\mathrm{o}}\right)\right\}$ são coeficientes desconhecidos e estimados pela solução do sistema de equações da KI. O preditor da krigagem possui as propriedades estatísticas de não tendenciosidade e erro quadrático da predição mínimo.

O número de pontos de água e o tempo de encanamento do domicílio foram estimados espacialmente na área de estudo usando-se a krigagem ordinária (KO). Esse método é similar à KI, mas aplicado para variáveis contínuas. Embora essas duas variáveis não sejam contínuas, foram consideradas como uma aproximação. O algoritmo da krigagem foi implementado usando-se uma grade regular com retículas quadradas de 10 metros de lado.

Os resultados da estimativa espacial foram avaliados por meio validação cruzada. Esse método reestima os valores da amostra por intermédio da krigagem e do modelo ajustado de semivariograma. Para as variáveis indicadoras, os valores reestimados pela validação cruzada foram categorizados usando-se como corte a prevalência achada em cada variável. Para as variáveis contínuas, foram analisados os resíduos das estimativas.

Os cálculos geoestatísticos foram realizados utilizando-se o programa GSLIB 2.0 (http:/ / www. gslib.com). As grades estimadas foram integradas ao programa ArcView GIS 3.2 (Environmental Systems Research Institute, Redlands, Estados Unidos) para a geração de mapas.

A associação estatística entre hepatite A e as variáveis foi testada por meio da razão de chances (odds ratio) com um intervalo de 95\% de confiança, e o teste de $\chi^{2}$ para um nível de significância de $5 \%$. Os programas estatísticos usados foram o Epi-Info 6.0d (Centers for Disease Control and prevention, Atlanta, Estados Unidos) e o S-PLUS 2000 (Mathsoft Inc., Seattle, Estados Unidos).

O presente trabalho foi aprovado pelo Comitê de Ética em Pesquisa do NESC/UFRJ, tendo em vista o que dispõe a Resolução $n^{o}$. 196/96 do Conselho Nacional de Saúde, sob o processo no. 040/01.

\section{Resultados}

A soroprevalência de hepatite A foi de $24 \%$, totalizando 312 casos positivos. Os setores censitários 117 e 110 apresentaram as maiores prevalências $(49,4 \%$ e $27,7 \%$, respectivamente). Incluíam-se na faixa etária igual ou maior que um ano até cinco anos 66,5\% das crianças, e 50,7\% eram do sexo feminino. Entre os domicílios, 38,6\% usavam poços perfurados ou escavados; $66,9 \%$ tinham ligação com a rede de abastecimento de água da CEDAE; $83,3 \%$ possuíam encanamento e destes em $36,7 \%$ o tempo de encanamento era menor que cinco anos. Pela rede geral recebiam água $61,4 \%$ dos domicílios; $38 \%$ possuíam entre um e quatro pontos de água. A água de poço era consumida por $33 \%$ e $45,3 \%$ não possuíam filtro. A fervura da água não era realizada por $79,5 \%$ dos moradores e 73,1\% não usavam cloro ou similares na água. Com relação ao esgoto sanitário, em $55,8 \%$ o destino era a rede geral, pluvial ou 
outra rede e $42,1 \%$ enviavam os dejetos sanitários para a via pública, vala negra, rio, mar, lagoa, sumidouro e outros. Tinham proximidade de vala negra, lixão ou ambos, 50,6\% dos domicílios. A maior parte das residências estava localizada em região de baixada. A Tabela 1 resume as variáveis associadas significativamente à hepatite $\mathrm{A}$.

A análise exploratória das variáveis mostrou que o número de pontos de água e o tempo de encanamento do domicílio possuíam histogramas não simétricos. Nesse caso, procedeu-se a transformação dessas variáveis em valores de uma distribuição normal padronizada usandose a transformação Nscore 22. A análise da continuidade espacial e da estimativa espacial foi feita com base em valores transformados. Os mapas finais foram obtidos na escala original da variável aplicando-se a transformação inversa Backtr 22 às estimativas da krigagem.

Os semivariogramas experimentais e os modelos ajustados estão especificados na Figura 2. Os semivariogramas direcionais não apresentaram padrão anisotrópico nas direções consideradas.

Considerando-se um raio de busca de $50 \mathrm{~m}$, a Figura 3 mostra os mapas para o risco de hepatite A e das variáveis sócio-econômicas.

A estimativa espacial da hepatite A apresentou uma sensibilidade de $61,3 \%$ e uma especificidade de 59,5\%, representando uma acurácia de $59,9 \%$. Em relação ao não uso de filtro, o modelo teve uma sensibilidade de $77,4 \%$ e uma especificidade de $73,5 \%$, resultando numa acurácia de $75,4 \%$. Os histogramas dos resíduos para o tempo de encanamento e o número de pontos de água apresentaram simetria em torno do zero e, aproximadamente, $55 \%$ dos resíduos se concentraram no intervalo de -0,5 a 0,5 (Figura 4).

\section{Discussão}

A área de estudo apresentou condições precárias de desenvolvimento social e econômico com uma baixa infra-estrutura em relação à coleta de lixo, ao abastecimento de água e ao destino do esgoto sanitário. Dentre as variáveis que elevaram o risco de hepatite A sobressaem as relacionadas à deficiência ou ausência de serviços de água. A população encontrada na região de estudo era de baixa renda, com domicílios de alvenaria em sua maioria, e um grande número de moradores por cômodo. Crianças com idade maior que cinco anos apresentaram maior risco, pois estiveram mais tempo expostas aos fatores de risco.

A variografia da hepatite A mostrou um alcance de $20 \mathrm{~m}$, aproximadamente. Esse fato indica que a ocorrência dos casos positivos de hepatite A se concentra em domicílios vizinhos. Observando os mapas, as áreas de alto risco para hepatite A tendem a coincidir com as de alto o risco de não uso de filtro, possivelmente porque esta variável tende a ser uma proxy do estado sócio-econômico do lar onde vive a criança. Quanto aos serviços de água, observa-se que áreas com ausência destes serviços estão presentes na maioria dos setores.

Este estudo apresentou um método para estimar a distribuição espacial de uma doença quando dispomos de informação no nível individual. O entendimento da distribuição espacial das doenças permite otimizar as medidas de controle especialmente aquelas que possuem influência sócio-ambiental em sua determinação como é o caso da hepatite A. A utilização do método de estimativa espacial por meio da krigagem possibilitou a detecção de áreas com maior probabilidade de ocorrência da hepatite $\mathrm{A}$, independente

Fatores associados à soroprevalência de hepatite A. Duque de Caxias, Rio de Janeiro, Brasil, 1997.

\begin{tabular}{|c|c|c|c|c|}
\hline Fatores & Positivos (\%) & Negativos (\%) & OR (IC95\%) & Valor de $p$ \\
\hline Idade (> 5 anos) & 62,1 & 24,4 & $5,08(3,84-6,73)$ & 0,000 \\
\hline Ausência de ligação de água com a CEDAE & 35,8 & 11,8 & $4,16(3,02-5,72)$ & 0,000 \\
\hline Ausência de pontos de água no domicílio & 18,5 & 9,8 & $2,09(1,45-3,03)$ & 0,000 \\
\hline Ausência de encanamento de água & 26,5 & 15,1 & $2,02(1,45-2,81)$ & 0,000 \\
\hline Ausência de cozinha & 12,5 & 6,9 & $1,90(1,22-2,94)$ & 0,002 \\
\hline Ausência de banheiro & 6,1 & 3,3 & $1,89(1,00-3,58)$ & 0,003 \\
\hline Não uso de filtro & 57,0 & 41,5 & $1,87(1,43-2,43)$ & 0,000 \\
\hline Densidade de moradores por cômodo $(>0,8)$ & 52,1 & 41,1 & $1,76(1,34-2,29)$ & 0,000 \\
\hline Altitude do domicílio (> 30 metros) & 31,1 & 21,8 & $1,62(1,11-2,38)$ & 0,009 \\
\hline Renda familiar (<2 salários mínimos) & 53,2 & 39,5 & $1,75(1,19-2,56)$ & 0,003 \\
\hline
\end{tabular}

CEDAE: Companhia Estadual de Águas e Esgotos do Rio de Janeiro. 
Figura 2

Semivariogramas experimentais direcionais e modelo ajustado para as variáveis: tempo de encanamento, número de pontos de água, hepatite A e não uso de filtro (omnidirecional). Duque de Caxias, Rio de Janeiro, Brasil, 1997.

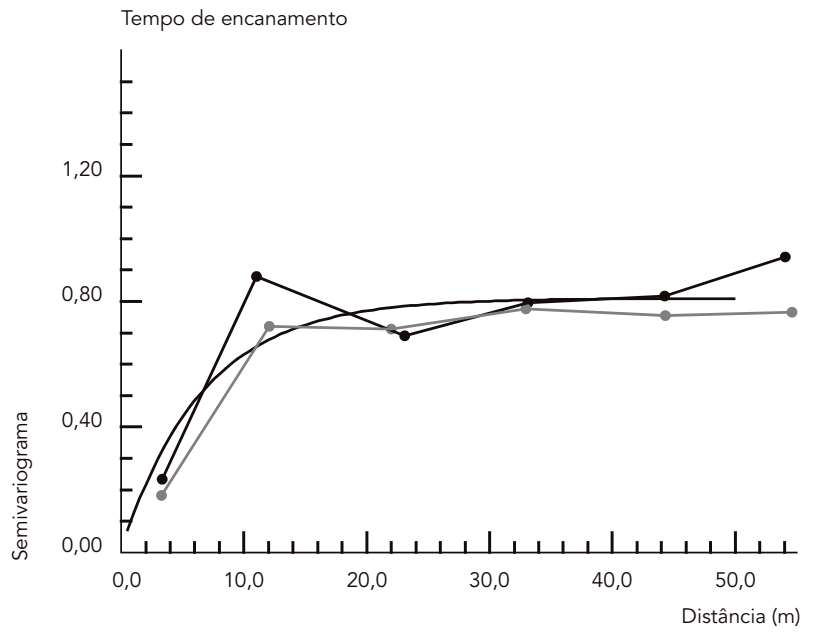

$\begin{array}{ll}\text { Modelo } & \text { Exponencial } \\ \text { Efeito Pepita } & 0,01 \\ \text { Alcance } & 20 \mathrm{~m} \\ \text { Patamar } & 0,081\end{array}$

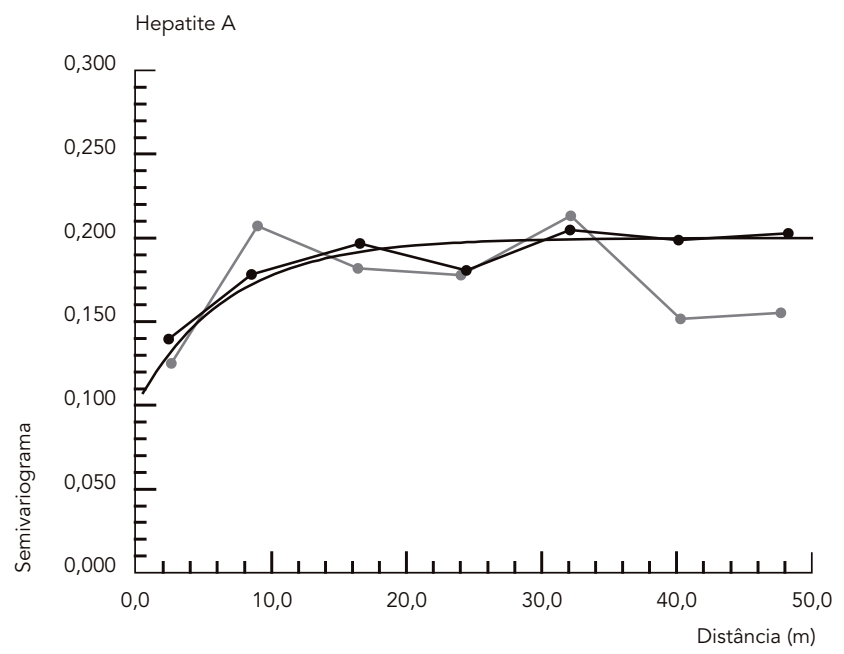

$\begin{array}{ll}\text { Modelo } & \text { Exponencial } \\ \text { Efeito Pepita } & 0,010 \\ \text { Alcance } & 20 \mathrm{~m} \\ \text { Patamar } & 0,20\end{array}$

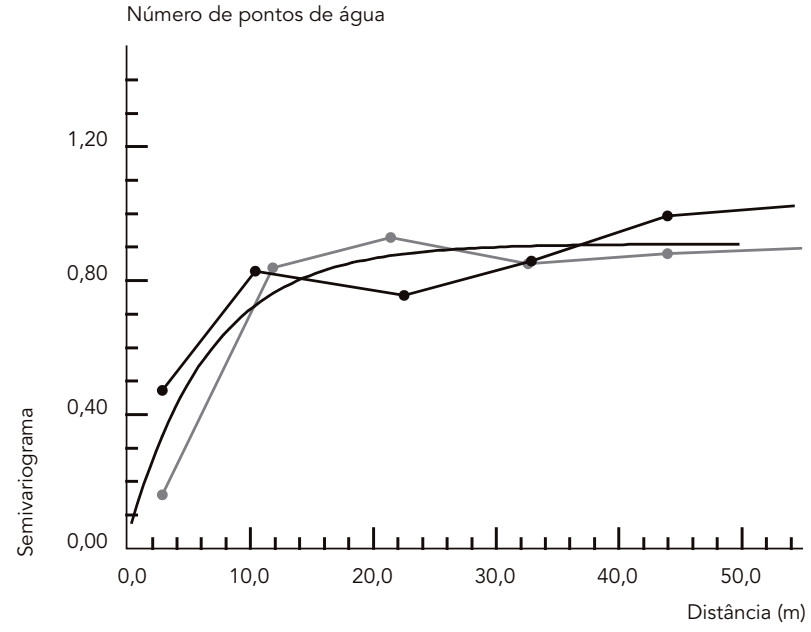

Modelo

Efeito Pepita Exponencial

$\begin{array}{ll}\text { Alcance } & 0,01 \\ \text { Patama } & 20 \mathrm{~m}\end{array}$

Patamar $\quad 0,081$

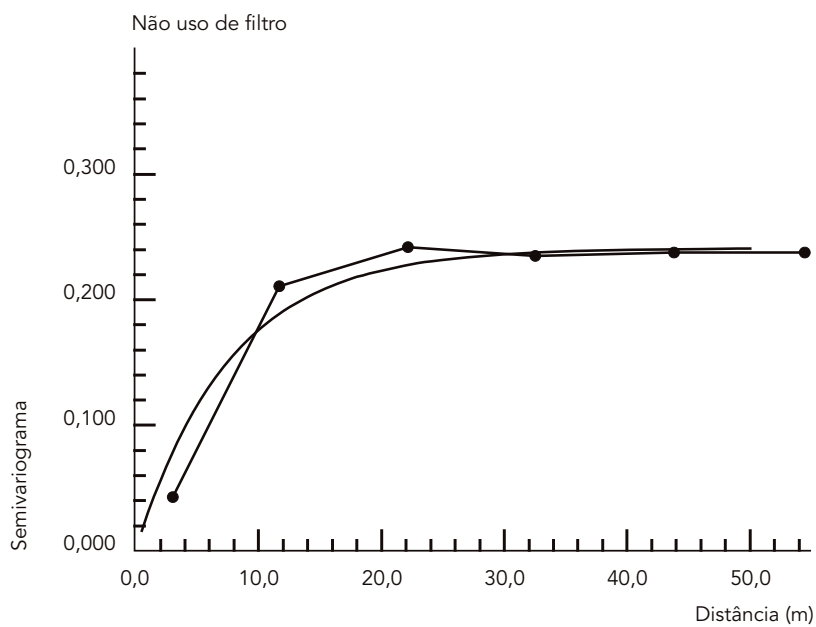

$\begin{array}{ll}\text { Modelo } & \text { Exponencial } \\ \text { Efeito Pepita } & 0,001 \\ \text { Alcance } & 23 \mathrm{~m} \\ \text { Patamar } & 0,24\end{array}$

- Modelo ajustado

$\longmapsto$ Norte-Sul

$\bullet$ Leste-Oeste 
Mapas da krigagem ordinária para o tempo de encanamento e o número de pontos de água, e mapas da krigagem indicadora para a hepatite $\mathrm{A}$ e o não uso de filtro. Duque de Caxias, Rio de Janeiro, Brasil, 1997.
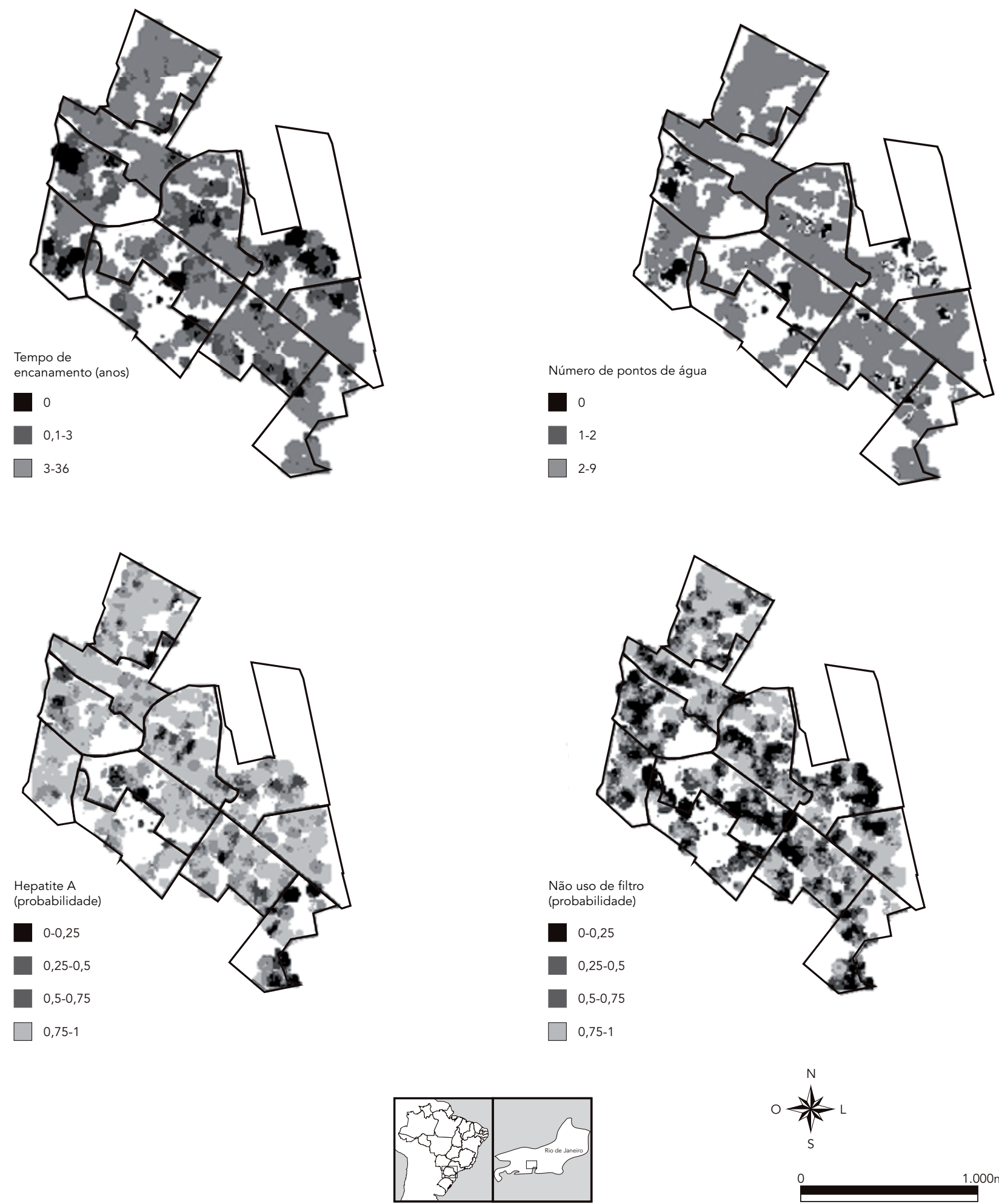

0 s $_{\mathrm{s}}^{\mathrm{N}}$

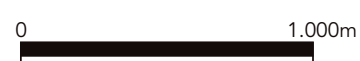


Figura 4

Histograma dos resíduos para o número de pontos de água (a) e o tempo de encanamento (b).
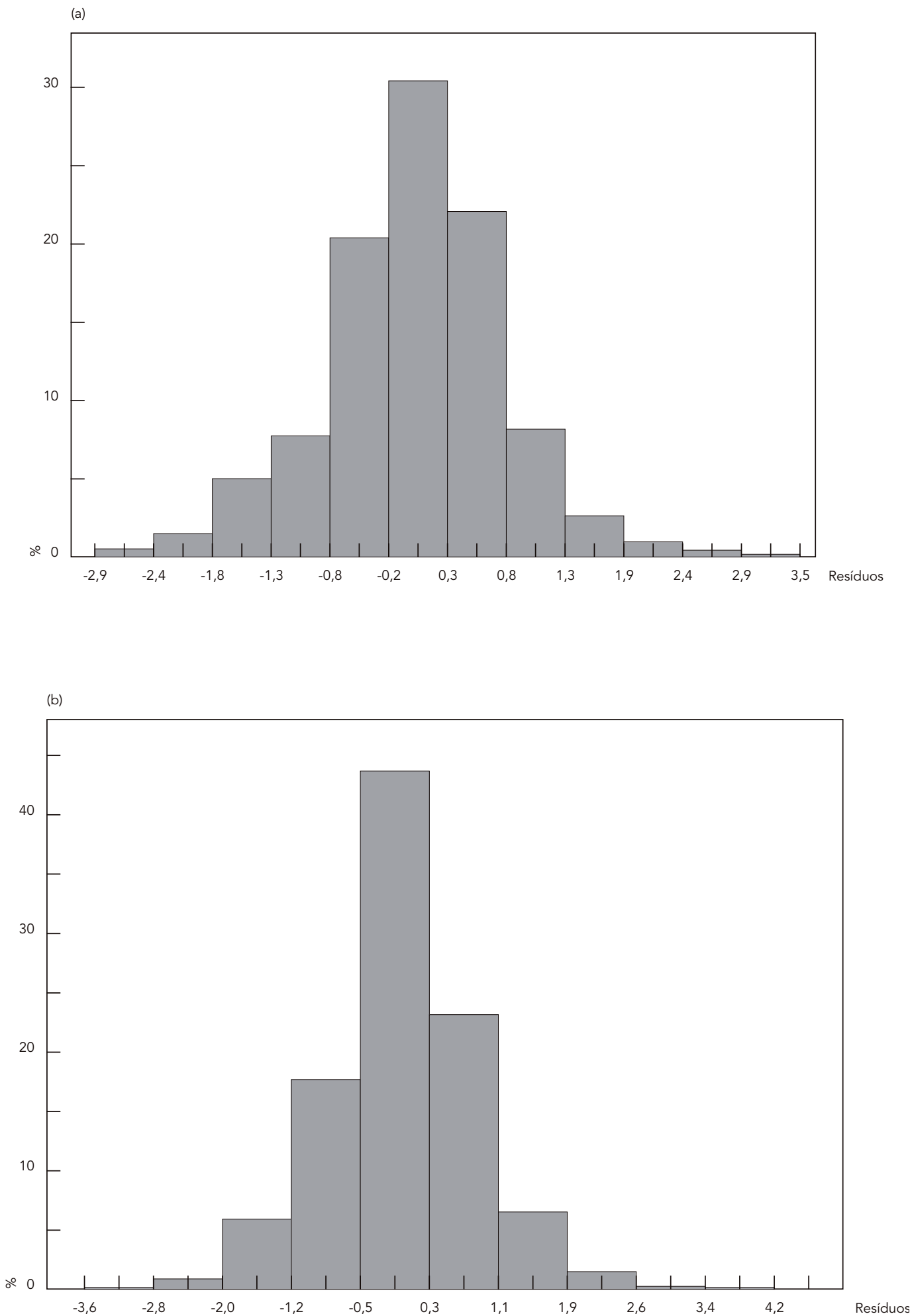
dos limites de divisão político administrativa dos setores censitários.

A realização do trabalho de campo foi definitiva para que se pudesse realizar as plotagens dos domicílios selecionados, bem como observar diretamente as condições sócio-econômicas, sanitárias e ambientais vividas pela população.

\section{Resumo}

Este estudo estimou áreas de risco de hepatite A e de variáveis associadas em região de Duque de Caxias, Rio de Janeiro, Brasil. Foi realizado um inquérito soroepidemiológico para hepatite A e domiciliar em 19 setores censitários. Destes, foram selecionados 11 setores contíguos com diferentes cotas altimétricas e todas as 1.298 crianças com idade menor que dez anos foram incluidas no estudo. Construiu-se semivariogramas para a hepatite A, não uso de filtro, número de pontos de água e tempo de encanamento de água. A estimativa espacial foi obtida por krigagem indicadora e ordinária. O ajuste dos modelos foi avaliado por meio de validação cruzada. Os quatro modelos ajustados de semivariogramas do desfecho e das três variáveis sócio-econômicas apresentaram um padrão isotrópico; mapas do risco estimado segundo a krigagem para hepatite A e para as variáveis sócio-econômicas foram construídos; a validação cruzada mostrou um bom ajuste. A utilização do método de estimativa espacial usando-se a krigagem possibilitou a detecção de áreas com maior probabilidade de ocorrência da hepatite A, independentemente da divisão político-administrativa dos setores censitários.

Hepatite A; Zona de Risco; Sistemas de Informação Geográfica
Com base nos resultados obtidos neste estudo, será possível aos governantes obter subsídios para uma tomada de decisão para essa região, permitindo assim uma promoção da melhoria da qualidade de vida da população do Parque Fluminense.

\section{Colaboradores}

R. C. C. Braga participou no georreferenciamento dos dados, na análise dos dados, na edição dos mapas e na confecção do artigo. L. I. O. Valencia participou na análise dos dados, na modelagem estatística e na confecção dos mapas. R. A. Medronho participou na análise dos dados, na edição dos mapas e na confecção do artigo. C. C. Escosteguy participou na análise dos dados e na confecção do artigo. Todos os autores participaram da revisão do artigo. 


\section{Referências}

1. Pereira FEL, Gonçalves CS. Hepatite A. Rev Soc Bras Med Trop 2003; 36:387-400.

2. Cockayne EA. Catarrhal jaundice, sporadic and epidemic and its relation to acute yellow atrophy of the liver. Q J Med 1912; 6:1-29.

3. Sobsey MD, Shileds PA, Hauchman FS. Survival and persistence of hepatitis A virus in environmental samples. In: Zuckerman AJ, editor. Viral hepatitis and liver disease: proceedings. New York: Wiley-Liss; 1988. p. 121-4.

4. Lednar WM, Lemon SM, Kirkpatrick JW, Redfield RR, Fields ML, Kelley PW. Frequency of illness associated with epidemic hepatitis A virus infection in adults. Am J Epidemiol 1985; 122:226-33.

5. Hadler SC, McFarland L. Hepatitis in day care centers: epidemiology and prevention. Rev Infect Dis 1986; 8:548-57.

6. Heymann DL. Control of communicable diseases manual. 18th Ed. Washington DC: American Public Health Association; 2004.

7. Viral Hepatitis Prevention Board. News from the VHPB meeting in St. Julians, Malta. Viral Hepatitis 1997; 6:1.

8. Medronho RA, Ribeiro SV, Valencia LIO, Fortes BPMD, Braga RCC. Análise espacial da soroprevalência da hepatite $\mathrm{A}$ em crianças de uma região carente de Duque de Caxias, RJ, Brasil. Rev Bras Epidemiol 2003; 6:328-34.

9. Trinta KS, Liberto MI, De Paula VS, Yoshida CF, Gaspar AMC. Hepatitis E virus infection in selected Brazilian populations. Mem Inst Oswaldo Cruz 2001; 96:25-9.

10. Struchiner CJ, Almeida LM, Azevedo RS, Massad E. Hepatitis A incidence rate estimates from a pilot seroprevalence survey in Rio de Janeiro, Brazil. Int J Epidemiol 1999; 28:776-81.

11. Luiz RR, Almeida RMVR, Almeida RT, Almeida LM. The relation between anti-hepatitis A virus antibodies and residence water access in Rio de Janeiro, Brazil. Int J Hyg Environ Health 2003; 206: 575-82.

12. Almeida LM, Amaku M, Azevedo RS, Cairncross S, Massad E. The intensity of transmission of hepatitis A and heterogeneities in socio-environmental risk factors in Rio de Janeiro, Brazil. Trans R Soc Trop Med Hyg 2002; 96:605-10.
13. Queiroz DA, Cardoso DD, Martelli CM, Martins RM, Porto SO, Azevedo MS, et al. Seroepidemiology of hepatitis A virus infection in street children of Goiânia, Goiás. Rev Soc Bras Med Trop 1995; 28:199-203.

14. Gaze R, Carvalho DM, Werneck GL. Soroprevalência das infecções pelos vírus das hepatites A e B em Macaé, Rio de Janeiro, Brasil. Cad Saúde Pública 2002; 18:1251-9.

15. Clarke KC, McLafferty SL, Tempalski BJ. On epidemiology and geographic information systems: a review and discussion of future directions emerging infectious diseases. Emerg Infect Dis 1996; 2:85-92.

16. Nuckols JR, Ward MH, Jarup L. Using geographic information systems for exposure assessment in environmental epidemiology studies. Environ Health Perspect 2004; 112:1007-15.

17. Fortes BPMD, Valencia LIO, Ribeiro, SV, Medronho RA. Modelagem geoestatística da infecção por Ascaris lumbricoides. Cad Saúde Pública 2004; 20:727-34.

18. Cressie NR. Statistics for spatial data. New York: John Wiley \& Sons Inc.; 1993.

19. Almeida LM, Costa MCE, Raggio LR, Coletty PE, Azevedo RS, Machado VA, et al. Soroprevalência da hepatite A no Município de Duque de Caxias, Rio de Janeiro, Brasil. Cad Saúde Coletiva 1998; 6 Suppl 1:39-48.

20. Almeida LM, Werneck GL, Cairncross S, Coeli CM, Costa MC, Coletty PE. The epidemiology of hepatitis A in Rio de Janeiro: environmental and domestic risk factors. Epidemiol Infect 2001; 127:327-33.

21. Almeida LM, Azevedo RS, Guimarães AA, Coutinho ES, Struchiner CJ, Massad E. Detection of antibodies against hepatitis A virus in eluates of blood spotted on filter-paper: a pilot study in Rio de Janeiro, Brazil. Trans R Soc Trop Med Hyg 1999; 93:401-4.

22. Deutsch CV, Journel AG. GSLIB: geostatistical software library and user's guide. $2^{\text {nd }}$ Ed. New York: Oxford University Press; 1998.

\section{Recebido em 09/Nov/2005}

Versão final reapresentada em 29/Dez/2007

Aprovado em 14/Jan/2008 